\title{
Community Security With Widely Available Information Technology
}

\author{
Yusaku Fujii \\ Gunma University < fujii@el.gunma-u.ac.jp > \\ Noriaki Yoshiura \\ Gunma University < yoshiura@1ab.cc.gunma-u.ac.jp > \\ Naoya Ohta \\ Gunma University< ohta@cs.gunma-u.ac.jp >
}

\begin{abstract}
We contend that a community will have a strong ability to prevent crime only if some residents keep watch on what happens around their houses with the aid of their own home computers, inexpensive and commercially available cameras, and free software. Under this scheme, residents would view their surroundings using cameras as their "eyes" and home computers as their "brains" Community safety would thus be realized by the voluntary cooperation and altruism of ordinary citizens using widespread technology.
\end{abstract}

A community with some residents keeping occasional watch around their houses has the potential to inhibit crime. In days gone by, there were many communities like this. However, in our times, individualism has become increasingly common, resulting in a lack of eyewitnesses to crimes in our communities. At the same time, security camera systems are now widely used and have an important role in reducing crime and identifying suspects. As for the typical usage of the security cameras, many problems seem to arise from the fact that they are introduced only for the benefit of their owners. One problem is that it is expensive to obtain a complete surveillance of an owner's property. A second problem is that the typical system usually keeps watch only inside the owner's property, so it cannot help with the overall safety of the community. A third problem is that neighbors may have concerns about their privacy if their property is under surveillance by someone else's security system. We argue that these problems may be solved if the camera systems are introduced within an altruistic community-minded framework.

We contend that a community will have a strong ability to prevent crime only if some residents keep watch on what happens around their houses with the aid of their own home computers, commercially available and affordable cameras, and free software. Many types of software for capturing video images are available; however, we could not find any that were available at no cost and would be suitable for the concept of community-wide security. Therefore, we have developed an application that provides the minimum functions needed, and currently distribute it free of charge through our Society for e-JIKEI Network website (http://www.e-jikei.org/index e.htm). The software, written in English and in Japanese, selects relevant pictures from a security camera and saves them to a hard disk (Fujii, Yoshiura, Chigira, \& Hagiwara, 2004). Our community-wide security concept, and the e-JIKEI Network system that embodies it, have been discussed from the viewpoints of social science (Fujii, Yoshiura, \& Ohta, 2005a) and homeland security (Yoshiura, Fujii, \& Ohta, 2005b). 
If the concept of the e-JIKEI Network is accepted, the security of the whole community would be covered, with the voluntary cooperation of the many residents who use the system. The main features of the e-JIKEI Network Project can be summarized as follows. Each constituent element of the network is voluntarily introduced and maintained by each citizen not for personal benefit, but on behalf of the entire community. Each element watches not the interior of a property, such as a house or shop, but around the outside of the property. All of the tools and resources provided through our web site are offered free of charge. Most types of commercial cameras can be used in the system. The role of mass media is very important; the e-JIKEI Network Project has already been heavily covered by newspapers, TV and radio, even though only preliminary experiments have been conducted in and around the city of Kiryu. Finally, we assume that the formation of a watch system covering the whole community can contribute to national security.

The first version of our free software, called "Dairi EYE standard," has been formally released. Its features are very limited, but they adequately cover the essential functions for community-wide security:

- High stability: Continuous running of more than 100 days has been confirmed.

- High operationality of file storage: The file name and its path express time and location information.

- Minimal required storage: Simple picture selection software has been adapted. The software saves a picture only when the difference between two consecutive images exceeds a specified threshold.

- Automatic delete: Folders that are older than the save period set by the owner are automatically deleted. Compatibility with many types of camera: Software can operate in the VFW mode (PC cameras and USB video adapters) and FTP mode (network cameras).

- Simultaneous operation: Software can operate several cameras connected to a single PC.

- No Internet connection: Due to privacy concerns, the software we have distributed does not connect to the Internet. Nonetheless, the e-JIKEI Network can be formed, in which the word "Network" refers not to the Internet but to the social network of the residents.

If the system of security cameras connected to computers and the Internet spreads nationwide, it could result in a powerful and flexible sociotechnical infrastructure whose participants help reduce crime through the use of software that is easy to install and upgrade. This infrastructure offers an important testbed for both social research and application development. In the near future, more intelligent functions could be achieved, such as detecting ambiguous motion, sending alerts to the police, and the comparison of facial images with the photos of known criminals. In serious crimes, such as kidnapping, improved rates of rescue and apprehension might be possible, if the majority of citizens give the police permission to access their individual surveillance systems. A country with many local communities having this facility could obtain improvements in homeland security. In this realm, our project (Yoshiura, Fujii, \& Ohta, 2005b) complements others, such as the more usual security camera systems and the US Home Guard (http://www.ushomeguard.org/), in which ordinary citizens register and then keep watch over critical infrastructure facilities from their homes, with the use of internet cameras.

The technology required to realize the e-JIKEI Network is not novel, but it was not available a decade ago. Today, the realization of the e-JIKEI Network will be much easier and its functionality stronger and more varied. For example, since the concept of the Network is that citizens should remain vigilant and not miss crimes that may occur right in front of their houses, automobile-based (and even wearable) systems might also be desirable. The performance of computer systems in cars is increasing rapidly; in the near future, keeping watch from cars will be quite feasible.

Although the e-JIKEI Network Project is in its early stages, some applications have been introduced into settings of realistic practice. For example, the city of Kiryu has decided to introduce the e-JIKEI Network in all 40 public schools of the city within the next two years. In this introduction in schools, the eJIKEI Network was introduced as an inexpensive, high-performance security camera system. However, we proposed that the system introduced in schools could also be used as an example for parents who would, in a united effort, watch the school district by installing the system in their homes. The Gunma Housing Supply Corporation has introduced the e-JIKEI Network in an exclusive residential district with 200 new 
houses. They have asked the homeowners who reside at important positions to use the system for the security of the whole district.

We have conducted many experiments in cooperation with a variety of other partners, such as the Kiryu Police Department, the city of Kiryu, and the NPO Higumi. Through the experiments, it has been proven that the system is easy to realize with widely available modern technology and that the e-JIKEI Network is efficient for crime prevention. When citizens have been informed of the potential effects of using available technology for crime prevention, each person will need to think carefully about whether and how to adopt the system and participate in its use. Moreover, improved technology in the near future will make it much easier to realize the e-JIKEI Network. Every person could have multiple cameras, controlled by high-performance computers, integrated in locations such as their cars, houses, and cell phones. Based on the e-JIKEI Network concept, people would have the ability to keep watch themselves, if they chose to participate, with very little additional cost. This means that each citizen will have strong monitoring power and will have to be responsible for it. Sooner or later, careful consideration and clear decisions by all citizens will be required.

In promoting the concept of the e-JIKEI Network, privacy protection will be a serious and delicate issue. We have generated user guidelines as part of the conditions of use for the software, in which careful consideration of privacy issues is required. The users of the software are asked not to view the pictures obtained from the system unless they have a valid and pressing need to do so, so as to prevent them from accessing information about neighbors' behavior unnecessarily. If the concept becomes more widespread across the nation, new laws will be required for defining the rights of, and constraints on, the owner of each system, including their access to the large volume of information obtained.

In the e-JIKEI Network, no one can control the whole system, since each element in the system is under the strict control of an individual citizen. In other security camera systems typically in use today, however, such as those in London, a small number of owners have the ability to control the entire system. Thus, the society that introduces the e-JIKEI Network is a society controlled not by a single organization or person but by every citizen. In such a society, it is very difficult to commit a crime without being reported. We are currently surveying citizens to find out how they compare the responsibility of watching what happens around their houses with the risk of privacy violations. It is in this context that we are now commencing tests on the true value of our community-wide security concept.

\section{References}

Y. Fujii, Yoshiura, N, Chigira, Y, \& Hagiwara, K. (2004). Community security platform for individually maintained home computers: The e-Vigilante Network Project. In Proceedings of the 21st IEEE Instrumentation and Measurement Technology Conference (pp. 891-894). New York: IEEE.

Y. Fujii, Yoshiura, N, \& Ohta, N. (2005a). Creating a worldwide community security structure using individually maintained home computers: The e-JIKEI Network Project. Social Science Computer Review, 23(2), 250-258.

Y. Fujii, Yoshiura, N, \& Ohta, N. (2005b). Using the security camera system based on individually maintained computers for homeland security: The e-JIKEI Network Project. In Proceedings of the 22nd IEEE Instrumentation and Measurement Technology Conference (pp. 101-105). New York: IEEE. 